\title{
Childhood sleep disturbance and risk of psychotic experiences at 18: UK birth cohort
}

\author{
A. Thompson, S. T. Lereya, G. Lewis, S. Zammit, H. L. Fisher* and D. Wolke*
}

\section{Background}

Sleep disturbances are commonly reported in the psychosis prodrome, but rarely explored in relation to psychotic experiences.

\section{Aims}

To investigate the relationship between specific parasomnias (nightmares, night terrors and sleepwalking) in childhood and later adolescent psychotic experiences.

\section{Method}

The sample comprised 4720 individuals from a UK birth cohort. Mothers reported on children's experience of regular nightmares at several time points between 2 and 9 years. Experience of nightmares, night terrors and sleepwalking was assessed using a semi-structured interview at age 12 . Psychotic experiences were assessed at ages 12 and 18 using a semi-structured clinical interview.

\section{Results}

There was a significant association between the presence of nightmares at 12 and psychotic experiences at 18 when adjusted for possible confounders and psychotic experiences at $12(\mathrm{OR}=1.62,95 \% \mathrm{Cl} 1.19-2.20)$. The odds ratios were larger for those who reported persistent psychotic experiences.

\section{Conclusions}

The presence of nightmares might be an early risk indicator for psychosis.

\section{Declaration of interest}

None.

\section{Copyright and usage}

(C) The Royal College of Psychiatrists 2015. This is an open access article distributed under the terms of the Creative Commons Attribution (CC BY) licence.
In recent years there has been particular interest in the significance of psychotic experiences in the general population. The non-trivial rates of these experiences in non-clinical populations ${ }^{1-3}$ has led to the re-emergence of a continuum model of psychosis. ${ }^{4}$ Although recent research has suggested that the relationship between established risk factors for schizophrenia and psychotic experiences may be weaker than initially thought, ${ }^{2,5}$ the relevance of these subclinical experiences to early intervention strategies in psychosis remains important. ${ }^{6,7}$ Therefore researchers have continued to investigate risk factors and possible causal mechanisms for the development of these psychotic experiences. One such potential risk factor in children that can readily be identified by parents, children and professionals is disturbance of sleep. Early researchers were interested particularly in the boundaries between nightmares and psychotic phenomena ${ }^{8}$ and some have proposed dreams and nightmares as a potential model for psychotic phenomena. ${ }^{9}$ Specific difficulties with sleep quality ${ }^{10}$, sleep-wake rhythm ${ }^{11}$ and electrophysiological sleep architecture (such as sleep spindles) ${ }^{12}$ are commonly reported in patients with schizophrenia. Moreover, sleep disturbance is one of the commonest symptoms retrospectively reported by patients with schizophrenia as part of a prodrome of the disorder ${ }^{13}$ and has been shown to be of particular value in predicting development of psychosis in clinical high-risk individuals. ${ }^{14}$ We are aware of only one study that found that sleep disturbance reported by children attending a psychiatric clinic was associated with increased odds of a later diagnosis of schizophrenia; ${ }^{15}$ we know of no prospective data on the relationship between sleep and psychotic experiences.

The relationship between specific sleep disturbances such as parasomnias and psychosis would seem particularly important for a number of reasons. Some parasomnias such as hypnagogic and hypnopompic hallucinations are phenomenologically similar to hallucinations in the waking state. Other common parasomnias such as nightmares and night terrors have often been associated

*Joint senior authors with psychopathology. ${ }^{16,17}$ Cross-sectional studies have also suggested that nightmares are related to psychosis proneness or schizotypy. ${ }^{18,19}$

We have previously demonstrated a cross-sectional relationship between the presence of nightmares and night terrors and psychotic experiences at age $12 .{ }^{20}$ However, it is essential to determine whether parasomnias are possible precursors of psychotic experiences using longitudinal data. Therefore, we examined the relationship between the most common parasomnias in childhood, namely nightmares, night terrors and sleepwalking, reported both in early childhood and at the age of 12 to later psychotic experiences reported at 18 years using data from a large UK birth cohort. It was hypothesised that all types of parasomnia would be associated with both the development and persistence of psychotic experiences during late adolescence.

\section{Method}

\section{Participants}

The Avon Longitudinal Study of Parents and Children (ALSPAC) is a birth cohort study, set in the UK, examining the determinants of development, health and disease during childhood and beyond. ${ }^{21,22}$ Briefly, women who were resident in Avon, UK while pregnant, and had an expected delivery date between 1 April 1991 and 31 December 1992 were approached to participate in the study, leading to the inclusion of 14775 live births with 14701 of these alive at 1 year of age. From the first trimester of pregnancy parents completed postal questionnaires about themselves and the study child's health and development. Children were invited to attend annual assessment clinics, including face-to-face interviews, psychological and physical tests from 7 years of age onward. Please note that the study website contains details of all of the data that is available through a fully searchable data dictionary (http://www. bris.ac.uk/alspac/researchers/data-access/data-dictionary/). This analysis is based on 4720 children who completed the PsychosisLike Symptoms semi-structured interview (PLIKSi) at 
approximately 18 years of age. Ethical approval for the study was obtained from the ALSPAC Ethics and Law Committee and the local research ethics committees and informed consent was provided by all participants.

\section{Outcome variables}

Psychotic experiences at 18

The PLIKSi ${ }^{2,3}$ is a semi-structured face-to-face interview conducted in private with the study member. The PLIKSi comprises 12 core questions eliciting key psychotic experiences covering hallucinations (visual and auditory), delusions (spied on, persecution, thoughts read, reference, control, grandiosity and other unspecified delusions) and experiences of thought interference (thought broadcasting, insertion and withdrawal) For these core items, seven stem questions were derived from the Diagnostic Interview Schedule for Children-IV (DISC-IV) ${ }^{23}$ and five from the Schedules for Clinical Assessment in Neuropsychiatry version 2.0 (SCAN 2.0). ${ }^{24}$ Cross-questioning was used to establish the presence of symptoms since 12 years of age, and coding followed the glossary definitions and rating rules for SCAN. The interviewers were psychology graduates trained in the use of the SCAN psychosis section and the PLIKSi. Items were assessed as not present, suspected or definitely present. The average kappa value for interrater reliability of rating psychotic experiences was 0.83 and the kappa for test-retest reliability was 0.76 . $^{3}$ Positive responses were probed for additional information including whether the experiences could be attributed solely to sleep or fever. Further detail on the instrument is available elsewhere. ${ }^{3}$ The main PLIKSi outcome was the presence of one or more of the PLIKSi experiences suspected or definitely present at age 18 . In order to rule out the possibility that any psychotic experiences associated with the parasomnias were only those that occurred when a child was falling asleep (hypnagogic), waking up (hypnopompic) or had a fever, only psychotic experiences that were not attributed to sleep or fever were used.

\section{Incident and persistent psychotic experiences}

The PLIKSi was also conducted with study members when they were 12 years of age ${ }^{2}$ to establish psychotic experiences occurring during the 6 months prior to interview. Suspected or definite psychotic experiences were identified with an average kappa value for interrater reliability of $0.72 .^{2}$ Using these data a further set of PLIKSi outcomes were created: (a) none - no psychotic experiences reported at age 12 or age 18; (b) incident - suspected or definite psychotic experiences present at 18 years but not present at 12 years; (c) remitted - suspected or definite psychotic experiences present at 12 years but not present at 18 years; and (d) persistent - suspected or definite psychotic experiences present at both 12 and 18 years. Again, these were excluding those experiences attributable to sleep or fever to remove this potential source of confounding.

\section{Predictor variables}

\section{Persistent nightmares during preschool and school}

Persistent nightmares during preschool and school were derived from postal questionnaires completed by mothers when the children were aged 2.5, 3.5, 4.75, 5.75, 6.75 and 9 years. Specifically, mothers were asked: 'In the past year, has your child regularly had nightmares?' The presence of nightmares at one time point, two time points and three or more time points $v$. no nightmares was considered here in order to assess the persistence of nightmares during the preschool and school period. Children were excluded from the analysis if they did not have nightmare data available for at least three time points. Other sleep disturbances during preschool and school at these time points (difficulty falling asleep and night waking) were also available in the cohort but were not associated with any measure of psychotic experiences at 12 (see Fisher et $\mathrm{al}^{25}$ ) or psychotic experiences at 18 and were not the focus of this paper.

\section{Sleeping problems at 12 years}

Sleeping problems at 12 years were assessed via face-to-face semistructured interviews with the children when they were aged on average 12.9 years old. The interviews were conducted by psychology graduates who were trained to a gold standard and attended a monthly clinic with the study's consultant psychiatrists to obtain consensus on difficult to rate cases. Children were asked a series of questions concerning sleeping problems (nightmares, night terrors and sleepwalking) during the 6 months prior to the interview based on DSM-IV ${ }^{26}$ criteria for sleeping disorders (for more information see Fisher et $a l^{20}$ ). Positive responses were probed to obtain further information to distinguish between nightmares and night terrors (for example when they occurred at night, amnesia upon awakening etc.). ${ }^{27}$ An overall rating of not present (0), suspected (1) or definitely (2) present was then made for each type of parasomnia based on all the information obtained. 'Definitely present' was rated when all criteria for a specific parasomnia were fulfilled and 'suspected' when most but not all criteria were fulfilled after probing. The average kappa value for interrater reliability was 0.72 . Sleeping problems coded overall as suspected or definitely present were used in the current analysis. Frequency of these experiences was measured as: only once or twice, quite often (monthly), often (almost weekly), most of the time (most days) and several times per night. Because of the number of responses this was simplified into three categories: none; only once or twice; and quite often, often or most of the time. Another variable was derived (any parasomnia) to reflect whether the children had reported any of these particular parasomnia symptoms (nightmare and/or night terror and/or sleepwalking) at 12 years of age.

\section{Confounders}

The following confounders were considered.

(a) IQ: an abbreviated form of the Wechsler Intelligence Scale for Children-III (UK version) ${ }^{28}$ was used to derive an overall IQ for the children who attended the ALSPAC clinic at age 8 .

(b) Family adversity: multiple family risk factors were assessed during pregnancy with the Family Adversity Index (FAI). ${ }^{29}$

(c) Psychiatric disorders: DSM-IV psychiatric diagnoses were made at 7 years using the Development and Well-Being Assessment (DAWBA $)^{30}$ based on parent and teacher reports. (d) Anxiety: DSM-IV diagnosis of an anxiety disorder at age 10 was made using the DAWBA ${ }^{30}$ based on parental reports.

(e) Depression: symptoms were assessed using the Short Mood and Feelings Questionnaire (SMFQ) ${ }^{31}$ administered at 10 (child report), 11.6 (mother report) and 12.6 (child report) years. The total score at each time point was collapsed into a dichotomous variable according to previously identified cut-points (scores of $<11$ indicated non-clinical symptoms, whereas scores of $\geqslant 11$ indicated clinically relevant depressive symptoms). ${ }^{32}$

(f) Child abuse: mothers reported via a series of postal questionnaires on whether their child had been physically 
hurt by someone and also whether their child had been sexually abused. Questionnaires were completed when the children were aged 2.5, 3.5, 4.8, 5.8 and 6.8 years. A positive response to either of these two questions at any of the time points was considered to indicate physical or sexual abuse.

(g) Enuresis: mothers reported via postal questionnaires on their child's bedwetting when the child was aged 4.5, 5.5, 6.5, 7.5 and 9 years. Reports of bedwetting for at least 1 week at any of these time points or still wearing a nappy at night at 5.5 years were taken to indicate the presence of enuresis.

\section{Statistical analyses}

Selective drop out was determined by comparing those who completed the PLIKSi at age 18 with those who did not, using binary logistic regression in the Statistical Package for the Social Sciences (SPSS) version 21. Analyses were repeated with the data weighted using inverse probability (of having missing outcome data) weights to account for those lost to follow-up. To assess whether persistence of nightmares during the preschool or school years or parasomnias at age 12 were associated with psychotic experiences at age 18, three sets of logistic regression analyses were conducted. Model A reported unadjusted analyses, model B controlled for the confounders described above and model C controlled for all confounders plus suspected/definite psychotic experiences without attributions at age 12 . Models A and B were repeated for the four-category persistence variables using multinomial regression. All analyses were conducted on individuals for whom all variables were available (outcomes, predictors and confounders).

\section{Results}

\section{Differences between participants with and without PLIKSi}

Differences in sociodemographic, family environment and child characteristics for ALSPAC participants with and without the PLIKSi at 18 years are shown in online Table DS1. Those who completed the PLIKSi were more often girls, came from less adverse family environments and were more likely to be born to mothers with a higher education level and living with partners in mortgaged properties. These children were also more likely to have a higher IQ at age 8 and less likely to have a DSM-IV psychiatric diagnosis at age 7 . However, children who attended the PLIKSi at age 18 were more likely to be depressed, to have been physically or sexually abused and have experienced more enuresis and persistent nightmares during preschool and school. No differences were found for children's sleeping problems (nightmares, night-terrors, sleepwalking or any parasomnia) or their psychotic experiences at age 12. In this study, we did not use any statistical method for imputing missing values but did repeat the analyses with data weighted to account for the selective drop out and did not find substantially different results (see online Tables DS2 and DS3). This study reports the results only for children who completed the PLIKSi at 18 years of age $(n=4720$; 2666 girls, $56.5 \%$ ).

\section{Prevalence of psychotic experiences and sleep problems}

At 18 years, $374(7.9 \%)$ from the entire sample of 4720 were judged to have one or more suspected or definite psychotic experiences not attributable to sleep or fever. Not all study members who had psychotic experiences data at 18 had data at 12. Out of 4060 study members with data at both time points,
190 study members (4.7\%) had suspected or definite psychotic experiences without any attributes only at age 18 (incident) and $100(2.5 \%)$ had psychotic experiences at both 12 and 18 years (persistent). Additionally, 370 (9.1\%) study members had suspected or definite psychotic experiences without any attributes only at age 12 (remitted).

Mothers of 1019 children (25.1\%) from the sample of 4060 never reported any nightmares for their children, 830 (20.4\%) reported children having regular nightmares at one time point, 708 $(17.4 \%)$ reported children having nightmares at two time points and $1503(37.0 \%)$ reported children having nightmares at three or more time points between 2.5 and 9 years. At age 12, 1010 $(24.9 \%)$ children reported having nightmares in the previous 6 months, $359(8.8 \%)$ reported having night terrors and 513 (12.6\%) reported sleepwalking in the past 6 months. Overall at 12 years, $1473(36.3 \%)$ children reported experiencing at least one type of parasomnia.

\section{Parasomnias and psychotic experiences at 18}

Prospective associations between childhood nightmares, parasomnias at age 12 and age 18 psychotic experiences are shown in Table 1. Persistent childhood nightmares, and any parasomnias, nightmares and night terrors at age 12 were associated with suspected/definite psychotic experiences at age 18 excluding those attributable to sleep and fever. However, once psychotic experiences at age 12 were controlled for, the associations for persistent childhood nightmares and night terrors were attenuated and just failed to reach conventional levels of statistical significance. Moreover, no association was found for age 12 sleepwalking. There does appear to be a relationship between increasing frequency of nightmares and night terrors and psychotic experiences demonstrated by increasing odds ratios at greater frequencies (online Tables DS4 and DS5), but the numbers in the analysis are small and these results should be interpreted with caution.

\section{Parasomnias and persistence of psychotic experiences}

Persistent childhood nightmares were significantly associated with new incidences of suspected/definite psychotic experiences at age 18 without attributions to sleep and fever (Table 2). However, the odds ratio was slightly attenuated and the confidence intervals included the null when all the confounders were added into the model. Nightmares and any parasomnias at age 12 were significantly associated with new incidences of suspected/definite psychotic experiences at age 18. All of the parasomnias were significantly associated with remitted psychotic experiences (psychotic experiences present only at age 12). Adjustment for potential confounders only slightly attenuated the associations. Persistent childhood nightmares, nightmares and night terrors at age 12 and any parasomnia at age 12 were significantly associated with persistent psychotic experiences (psychotic experiences present at both age 12 and 18) but sleepwalking at age 12 was not associated. Adjusting for potential confounders reduced the associations slightly.

Although in our sample parasomnias at 12 were more common in those with persistent psychotic experiences between 12 and 18 compared with those whose psychotic experiences had remitted at 18 , numbers were small and there was no evidence that this difference was more than that resulting from random error/chance (nightmares: $\mathrm{OR}=1.51,95 \%$ CI 0.87-1.64; night terrors: $\mathrm{OR}=1.65,95 \% \mathrm{CI} 0.82-3.34$; any parasomnia: $\mathrm{OR}=1.43$, 95\% CI 0.81-2.52). 
Table 1 Sleeping problems in childhood and suspected/definite psychotic experiences at 18 years excluding attributions to sleep and fever ${ }^{\mathrm{a}}$

\begin{tabular}{|c|c|c|c|c|}
\hline & \multirow[b]{2}{*}{$n$} & \multicolumn{3}{|c|}{ Psychotic experiences, OR (95\% Cl) } \\
\hline & & Model $A^{b}$ & Model $B^{C}$ & Model $C^{d}$ \\
\hline $\begin{array}{l}\text { Persistent nightmares, } 2.5-9 \text { years } \\
\text { Linear trend }\end{array}$ & 3036 & $1.19(1.06-1.35)$ & $1.16(1.03-1.32)$ & $1.13(0.99-1.28)$ \\
\hline Nightmares, 12 years & 3057 & & & \\
\hline No & & Reference & Reference & Reference \\
\hline Yes & & $2.14(1.59-2.87)$ & $1.92(1.42-2.58)$ & $1.62(1.19-2.20)$ \\
\hline Night terrors, 12 years & 3056 & & & \\
\hline No & & Reference & Reference & Reference \\
\hline Yes & & $1.93(1.28-2.91)$ & $1.71(1.13-2.60)$ & $1.52(0.99-2.34)$ \\
\hline Sleepwalking, 12 years & 3056 & & & \\
\hline No & & Reference & Reference & Reference \\
\hline Yes & & $1.24(0.83-1.84)$ & $1.19(0.79-1.78)$ & $1.11(0.73-1.67)$ \\
\hline Any parasomnias, 12 years & 3053 & & & \\
\hline No & & Reference & Reference & Reference \\
\hline Yes & & $2.00(1.50-2.66)$ & $1.82(1.36-2.43)$ & $1.60(1.19-2.16)$ \\
\hline $\begin{array}{l}\text { a. The reference group in all of the analy } \\
\text { sleepwalking at age } 12 \text {. } \\
\text { b. Unadjusted analysis. } \\
\text { c. Adjusted for gender, Family Adversity I } \\
\text { at } 2.5,3.5,4.8,5.8 \text { or } 6.8 \text { years, Developr } \\
\text { d. Adjusted for gender, FAl score, enures } \\
6.8 \text { years, DAWBA score at } 7 \text { years (any }\end{array}$ & $\begin{array}{l}\text { of parti } \\
\text { re, enur } \\
\text {-1eing A } \\
5,6.5,7 \\
\text { es), any }\end{array}$ & $\begin{array}{l}t \text { any sleeping problems } \\
\\
6.5,7.5 \text { or } 9 \text { years, } 1 Q \\
\text { WBA) Score at } 7 \text { years } \\
\text { Q at } 8 \text { years, depression } \\
r \text { diagnosis at } 10 \text { years }\end{array}$ & $\begin{array}{l}\text { nnia refers to reports of } \\
\text { pression score at 10, } 11 \\
\text { gnoses) and any anxiety } \\
11.6 \text { or } 12.6 \text { years, sexu } \\
\text { experiences at age } 12\end{array}$ & $\begin{array}{l}\text { es, night terrors or } \\
\text { rs, sexual or physical abus } \\
\text { nnosis at } 10 \text { years. } \\
\text { abuse at } 2.5,3.5,4.8,5.8 \\
\text { utes to sleep and fever. }\end{array}$ \\
\hline
\end{tabular}

Table 2 Childhood sleeping problems and persistence of suspected/definite psychotic experiences between 12 and 18 years excluding attributions to sleep and fever ${ }^{\mathrm{a}}$

\begin{tabular}{|c|c|c|c|c|c|c|c|c|c|}
\hline & \multirow[b]{2}{*}{$n$} & \multicolumn{4}{|c|}{ Unadjusted analyses, ${ }^{\mathrm{b}}$ OR $(95 \% \mathrm{Cl})$} & \multicolumn{4}{|c|}{ Adjusted analyses, ${ }^{\mathrm{C}} \mathrm{OR}(95 \% \mathrm{Cl})$} \\
\hline & & None & $\begin{array}{l}\text { Incident } \\
\text { (at } 18 \text { but } \\
\text { not 12) }\end{array}$ & $\begin{array}{l}\text { Remitted } \\
\text { (at } 12 \text { but } \\
\text { not } 18 \text { ) }\end{array}$ & $\begin{array}{c}\text { Persistent } \\
\text { (at } 12 \text { and 18) }\end{array}$ & None & $\begin{array}{l}\text { Incident } \\
\text { (at } 18 \text { but } \\
\text { not } 12 \text { ) }\end{array}$ & $\begin{array}{l}\text { Remitted } \\
\text { (at } 12 \text { but } \\
\text { not } 18 \text { ) }\end{array}$ & $\begin{array}{l}\text { Persistent } \\
\text { (at } 12 \text { and 18) }\end{array}$ \\
\hline Nightmares, 2-9 years & 3056 & Reference & $1.18(1.02-1.36)$ & $1.25(1.12-1.39)$ & $1.32(1.06-1.65)$ & Reference & $1.15(0.99-1.33)$ & $1.21(1.08-1.35)$ & $1.27(1.02-1.60)$ \\
\hline Nightmares, 12 years & 3057 & Reference & $1.83(1.28-2.63)$ & $2.85(2.20-3.69)$ & $4.31(2.59-7.17)$ & Reference & $1.69(1.17-2.44)$ & $2.71(2.08-3.53)$ & $3.87(2.30-6.51)$ \\
\hline Night terrors, 12 years & 3056 & Reference & $1.65(0.98-2.80)$ & $1.90(1.30-2.77)$ & $3.14(1.68-5.87)$ & Reference & $1.52(0.89-2.60)$ & $1.77(1.20-2.61)$ & $2.70(1.42-5.15)$ \\
\hline Sleepwalking, 12 years & 3056 & Reference & $1.35(0.84-2.16)$ & $1.65(1.19-2.31)$ & $1.22(0.59-2.49)$ & Reference & $1.33(0.83-2.14)$ & $1.63(1.16-2.28)$ & $1.12(0.54-2.31)$ \\
\hline Any parasomnias, 12 years & 3053 & Reference & $1.81(1.29-2.54)$ & $2.38(1.84-3.07)$ & $3.38(2.01-5.70)$ & Reference & $1.70(1.21-2.41)$ & $2.27(1.75-2.95)$ & $2.94(1.72-5.02)$ \\
\hline $\begin{array}{l}\text { a. The reference group in all } \\
\text { night terrors or sleepwalking } \\
\text { b. Unadjusted analysis. } \\
\text { c. Adjusted for gender, Fam } \\
3.5,4.8,5.8 \text { or } 6.8 \text { years, De }\end{array}$ & & $s i s$ & of partici & & & & & & ares, \\
\hline
\end{tabular}

\section{Discussion}

\section{Summary of the results}

Data from this large UK birth cohort suggest that those who have childhood experiences of nightmares and night terrors at age 12 are more likely to report psychotic experiences at age 18 . However, the relationship for night terrors was attenuated when a number of potential confounders were controlled for including age, IQ, childhood abuse, family adversity, early mood disturbance and also baseline psychotic experiences at age 12. The relationship with nightmares and subsequent psychotic experiences was also observed in measures of nightmares collected in early childhood although this relationship was attenuated when controlling for possible confounders.

\section{Comparison with previous studies}

The study confirms our previous finding of a cross-sectional relationship between nightmares and night terrors and psychotic experiences at age 12 but not sleepwalking. ${ }^{20}$ However, in this study the relationship with night terrors was weaker. It also extends the longitudinal findings of this study in that early childhood nightmares are associated with the development of psychotic symptoms both at age 12 and up to the later age of
18 but again the strength of the association is somewhat weaker. Other groups have examined the relationship between sleep and the broader concepts of schizotypy or psychosis proneness and found a similar relationship with nightmares. ${ }^{19,20}$ Indeed, Levin and colleagues concluded that 'nightmare experience may be a useful conjoint behavioural indicator for the early detection of schizophrenia-spectrum psychopathology. ${ }^{19}$ However, these studies have either been cross-sectional or used much smaller samples than this study. There have been no previous studies examining night terrors or sleepwalking and psychotic experiences longitudinally to our knowledge so these are novel findings. The association with types of parasomnia and psychotic experiences is similar to the findings of Koffel \& Watson ${ }^{33}$ who reported associations between unusual sleeping problems (including nightmares, vivid dreaming, narcolepsy symptoms and complex night-time behaviours) and schizotypy but not for other sleep disturbances (for example insomnia, lassitude/fatigue). However, this comparison is limited by the fact that we did not comprehensively assess insomnia or other types of routine sleep disturbance.

\section{Strengths and weaknesses}

The strengths of the study are the longitudinal nature of the data collection, the large sample size, the comprehensive approach to 
eliciting psychotic experiences and the ability to adjust for a number of potential confounders in the relationship between sleep disturbances and psychotic experiences. We were also able to exclude possible hypnagogic and hypnopompic hallucinations from our measure of psychotic experiences. However, there are a number of potential weaknesses of the study worth noting. We could not exclude psychotic experiences at 18 attributed to substance use. We were unable to exclude the presence of other parasomnias that may mimic nightmares/night terrors such as obstructive sleep apnoea and nocturnal epilepsy and we did not exclude individuals with other chronic organic conditions that could cause parasomnias, although this number is likely to be low in a healthy birth cohort. We did not have a satisfactory rating of insomnia in the cohort and measures of this and sleep quality would provide a more comprehensive picture of sleep difficulties as specific risk factors for psychotic symptoms. The rating of parasomnia symptoms at 12 was based on a semi-structured interview eliciting an example of the phenomenon and detailed probing. However, the prevalence of night terrors $(8.8 \%)$ and sleepwalking $(12.6 \%)$ found in the current sample at age 12 was higher than has previously been reported for children of a similar age. These types of parasomnia tend to become less frequent by late childhood and a study conducted by Laberge et $a l^{34}$ of a representative sample of children from Canada found that only $2.3 \%$ of them were still experiencing night terrors and only $6.8 \%$ were sleepwalking by 12 years of age. One possible reason for the discrepancy is that the current study utilised the young adolescent as the data source of sleeping difficulties whereas the Laberge et $a l^{34}$ study used parental reports. The parents of the young adolescents in the Canadian sample may not have been aware of any sleeping problems if they were not woken at the time. Similarly, many parents of infants are not aware of their child waking if they do not cry and alert the parents. ${ }^{35}$ There is a possibility that the self-report of night terrors and sleepwalking especially (where there is classically little memory for the event) may be subject to error. However, there is some evidence that the correlation between self-report and informant report for sleep difficulties in children is good ${ }^{36}$ and our assessment was using a semi-structured interview with raters trained to a gold standard and achieving a good interrater reliability on these items. The results of the relationship between parent reports of early experience of nightmares are also broadly similar to the child report at 12 . However, we would encourage replication of the results at age 12 using a combination of child report and parental report measures.

We also have limited information on the impact of the sleeping difficulties at age 12 and are therefore unable to comment on the role of distress in relation to these events in respect of psychotic experiences. There is also the issue of selective drop out from the original cohort. Nevertheless, empirical simulations demonstrate that even when drop out is correlated with predictor/ confounder variables, the relationship between predictors and outcome is unlikely to substantially be altered by selective dropout processes. ${ }^{37}$ Indeed, when the analyses were repeated after weighting for this selective drop out the results were very similar (online Tables DS1 and DS2). Although the results are only slightly attenuated by potential confounders in the relationship between sleep symptoms and psychotic experiences, we cannot be sure that we have accounted for all residual confounding factors. We are also aware we had limited power to investigate the question of whether those reporting persistent psychotic experiences were more likely to report earlier parasomnia symptoms compared with those whose psychotic experiences had remitted at 18 .

\section{Possible mechanisms}

Assuming our method of excluding those psychotic experiences that are related to falling asleep or waking did accurately exclude those individuals who had hypnopompic and hypnagogic hallucinations, then there are a number of possible explanations as to why nightmares in particular might be related to psychotic experiences to consider. These theories need to take into account that the relationship seems specific for nightmares and to some extent night terrors and not sleepwalking so it is not a general effect of this type of sleep disturbance. First, the boundaries between wake and sleep especially in rapid eye movement (REM) sleep may be important in relation to sleep and psychotic experiences. One particular hypothesis, for example is that the boundaries between being asleep and awake may be too 'flexible' in some individuals with psychosis resulting in brief lapses into REM sleep (within which nightmares are experienced) occurring while they are awake, resulting in the experience of hallucinations during the day. ${ }^{38}$ Conversely, slipping into a waking state while in non-REM sleep is postulated to account for the occurrence of night terrors and sleepwalking. However, although some studies have found poor sleep/wake boundaries among individuals with psychotic symptoms, ${ }^{39}$ there is little evidence of intrusions of REM sleep into waking states in patients with schizophrenia experiencing hallucinations. ${ }^{40}$ It is difficult to explain the results with regards to sleepwalking using this model and even if intrusions into REM sleep and not non-REM sleep are particularly important this fails to explain the results for night terrors, which results in intrusions into non-REM sleep. Similarly, dissociation, which is often seen as a common mechanism for both development of psychotic symptoms and parasomnias ${ }^{34}$ would not appear to adequately explain the negative finding with sleepwalking.

It has been suggested that there may be shared patterns of neuroanatomical, neurochemical and neurophysiological pathways occurring in nightmares and the positive symptoms of psychosis, for example, the finding that cortical dopamine levels are raised during nightmares ${ }^{41}$ and the functional significance of sleep spindles in psychosis $^{42}$ that are consistently reduced in schizophrenia. ${ }^{43}$ Some studies have also reported a continuity between dreams and psychotic experiences; with overlapping content ${ }^{44}$ and indistinct barriers between these experiences. ${ }^{45}$ This is related to the increased interest in dreams ${ }^{46}$ or REM sleep ${ }^{47}$ as a neurobiological model for schizophrenia or psychotic phenomena.

The presence of anxiety and depressive symptoms as confounding factors in those with sleep disturbance could potentially explain the findings. Higher levels of anxiety appear to be related to nightmares and night terrors but less strongly to sleepwalking, ${ }^{34}$ although these are still related in some patients. ${ }^{48}$ Anxiety symptoms may also be related to development of psychotic symptoms. ${ }^{49}$ However, the adjustment for anxiety symptoms at age 10 and depression at 10,11 and 12 did not significantly affect our results making this explanation less likely.

The relationship between traumatic experiences and parasomnia symptoms and psychotic experiences could be particularly important. Experience of stressful events has been related to both the development of nightmares ${ }^{50}$ and psychotic symptoms in late childhood. ${ }^{51,52}$ Nightmares are a diagnostic feature of post-traumatic stress disorder (PTSD, DSM- $5^{53}$ ) and there may be some specificity of nightmares to PTSD compared with other sleep disturbances. ${ }^{54}$ Therefore, the relationship could be as a result of an epiphenomenon of the experience of trauma, or trauma could be causing both experiences and could be a marker of the impact of the traumatic experience. A neurocognitive model of nightmares postulates a problem with fear extinction in those 
who experience nightmares ${ }^{55}$ and it may, for example, represent a shared mechanism for the production of particular psychotic symptoms. The relationship between nightmares (especially) and night terrors and trauma ${ }^{56}$ may be stronger than for sleepwalking, although sleepwalking can also be associated with traumatic psychological events. ${ }^{48}$ Unfortunately, there is not sufficiently good data available on significant trauma in the cohort to allow detailed exploration of this relationship at present; we are aware that only one individual in the cohort had a diagnosis of PTSD made using the DAWBA at age 7 (this individual did not report any psychotic experiences) and the measures of physical and sexual abuse were collected at an early age, were broad measures and were parental report. However, when adjusted for early levels of sexual and physical abuse in the analysis, this did not substantially change the results.

\section{Implications}

The clinical relevance of these findings may relate to the way that early nightmares (especially) and night terrors are viewed and potentially addressed by professionals or carers. It is likely that in some individuals, nightmares and night terrors have little significance to later psychopathology, however in individuals with additional risks such as a family psychiatric history or a past trauma exposure by adults or peers, ${ }^{51,57}$ such sleep problems may have greater significance and may also highlight other unnoticed psychopathology or trauma. There are also established brief evidence-based psychological treatments of nightmares such as imagery rehearsal therapy (IRT) ${ }^{58}$ and some medications for specific indications ${ }^{59}$ that could be considered to reduce the potential impact of nightmares on future psychopathology. Further work is needed to understand the mechanisms and interplay of risk factors, especially the role of trauma, in the relationship between these sleep disturbances and psychotic experiences. Despite this, these results suggest that specific parasomnias such as nightmares in children are a potential risk indicator for the development of psychopathology such as psychotic experiences.

\section{A. Thompson, MD, FRCPsych, Division of Mental Health and Wellbeing, University of Warwick, Coventry; S. T. Lereya, PhD, Department of Psychology, University of Warwick, Coventry; G. Lewis, PhD, MRCPsych, Division of Psychiatry, University College London, London; $\mathbf{S}$. Zammit, PhD, MRCPsych, MRC Centre for Neuropsychiatric Genetics and Genomics, Cardiff University, Cardiff and Centre for Academic Mental Health, School of Social and Community Medicine, University of Bristol, Bristol; H. L. Fisher, PhD, MRC Social, Genetic and Developmental Psychiatry Centre, Institute of Psychiatry, Psychology \& Neuroscience, King's College London, London; D. Wolke, PhD, Division of Mental Health and Wellbeing and Department of Psychology, University of Warwick, Coventry, UK \\ Correspondence: Andrew Thompson, Division of Mental Health and Wellbeing Warwick Medical School, University of Warwick, Coventry, CV47AL, UK. Email: Andrew.d.thompson@warwick.ac.uk}

First received 20 Dec 2013, final revision 12 Sep 2014, accepted 20 Oct 2014

\section{Funding}

The UK Medical Research Council (MRC) and the Wellcome Trust (grant 092731) and the University of Bristol provide core support for ALSPAC. Data collection was partly funded University of Bristol provide core support for ALSPAC. Data collection was partly funded
by an MRC grant (G0701503). D.W. and S.T.L.'s work on this study was supported by the Economic and Social Research Council (ESRC) grant ES/K003593/1. H.L.F. is funded by an MRC Population Health Scientist fellowship (G1002366). G.L. is an NIHR Senior Investigator. None of the funding bodies had any further role in the collection, analysis or interpretation of data, the writing of this manuscript, or the decision to submit this manuscript for publication.

\section{Acknowledgements}

We are extremely grateful to all the families who took part in this study, the midwives for their help in recruiting them, and the whole ALSPAC team, which includes interviewers, computer and laboratory technicians, clerical workers, research scientists, volunteers, managers, receptionists and nurses.

\section{References}

1 Kelleher I, Connor D, Clarke MC, Devlin N, Harley M, Cannon M. Prevalence of psychotic symptoms in childhood and adolescence: a systematic review and meta-analysis of population-based studies. Psychol Med 2012; 42: 1857-63.

2 Horwood J, Salvi G, Thomas K, Duffy L, Gunnell D, Hollis C, et al. IQ and non-clinical psychotic symptoms in 12-year-olds: results from the ALSPAC birth cohort. Br J Psychiatry 2008; 193: 185-91.

3 Zammit S, Kounali D, Cannon M, David AS, Gunnell D, Heron J, et al. Psychotic experiences and psychotic disorders at age 18 in relation to psychotic experiences at age 12 in a longitudinal population-based cohort study. Am J Psychiatry 2013; 170: 742-50.

4 van Os J, Hanssen M, Bijl RV, Ravelli A. Strauss (1969) revisited: a psychosis continuum in the general population? Schizophr Res 2000; 45: 11-20.

5 Zammit S, Horwood J, Thompson A, Thomas K, Menezes P, Gunnell D, et al. Investigating if psychosis-like symptoms (PLIKS) are associated with family history of schizophrenia or paternal age in the ALSPAC birth cohort. Schizophr Res 2008; 104: 279-86.

6 Kelleher I, Lynch F, Harley M, Molloy C, Roddy S, Fitzpatrick C, et al. Psychotic symptoms in adolescence index risk for suicidal behavior: findings from 2 population-based case-control clinical interview studies. Arch Gen Psychiatry 2012; 69: 1277-83.

7 Fisher $\mathrm{HL}$, Caspi A, Poulton R, Meier $\mathrm{MH}$, Houts $\mathrm{R}$, Harrington $\mathrm{H}$, et al. Specificity of childhood psychotic symptoms for predicting schizophrenia by 38 years of age: a birth cohort study. Psychol Med 2013; 43: 2077-86.

8 Jung C. On the psychogenesis of schizophrenia. J Ment Sci 1939; 85: 999-1011.

9 Scarone S, Manzone ML, Gambini O, Kantzas I, Limosani I, D'Agostino A et al. The dream as a model for psychosis: an experimental approach using bizarreness as a cognitive marker. Schiz Bull 2008; 34: 515-22.

10 Haffmans PM, Hoencamp E, Knegtering HJ, van Heycop ten Ham BF. Sleep disturbance in schizophrenia. Br J Psychiatry 1994; 165: 697-698.

11 Wulff K, Dijk D-J, Middleton B, Foster RG, Joyce EM. Sleep and circadian rhythm disruption in schizophrenia. Br J Psychiatry 2012; 200: 308-16.

12 Wilson S, Argyropoulos S. Sleep in schizophrenia: time for closer attention. Br J Psychiatry 2012; 200: 273-74.

13 Yung AR, McGorry PD. The initial prodrome in psychosis: descriptive and qualitative aspects. Aust N Z J Psychiatry 1996; 30: 587-99.

14 Ruhrmann S, Schultze-Lutter F, Salokangas RK, Heinimaa M, Linszen D, Dingemans $\mathrm{P}$, et al. Prediction of psychosis in adolescents and young adults at high risk: results from the prospective European prediction of psychosis study. Arch Gen Psychiatry 2010; 67: 241-51.

15 Cannon M, Walsh E, Hollis C, et al. Predictors of later schizophrenia and affective psychosis among attendees at a child psychiatry department. Br J Psychiatry 2001; 178: 420-6.

16 Levin R, Fireman G. Nightmare prevalence, nightmare distress, and selfreported psychological disturbance. Sleep 2002; 25: 205-12.

17 Ohayon MM, Guilleminault C, Priest RG. Night terrors, sleepwalking, and confusional arousals in the general population: their frequency and relationship to other sleep and mental disorders. J Clin Psychiatry 1999; 60: $268-76$

18 Claridge G, Clark K, Davis C. Nightmares, dreams, and schizotypy Br J Clin Psychol 1997; 36: 377-86.

19 Levin R. Nightmares and schizotypy. Psychiatry 1998; 61: 206-16.

20 Fisher $\mathrm{H}$, Lereya ST, Thompson A, Lewis G, Zammit S, Wolke D. Childhood parasomnias and psychotic experiences at age 12 in a UK birth cohort. Sleep 2014; 37: 475-82.

21 Boyd A, Golding J, Macleod J, Lawlor DA, Fraser A, Henderson J, et al. Cohort profile: the 'children of the $90 \mathrm{~s}^{\prime}$-the index offspring of the Avon Longitudinal Study of Parents and Children. Int J Epidemiol 2013; 42: $111-27$.

22 Fraser A, Macdonald-Wallis C, Tilling K, Boyd A, Golding J, Davey Smith G, et al. Cohort profile: the Avon Longitudinal Study of Parents and Children: ALSPAC mothers cohort. Int J Epidemiol 2013; 42: 97-110.

23 Shaffer D, Fisher P, Lucas CP, Dulcan MK, Schwab-Stone ME. NIMH Diagnostic Interview Schedule For Children Version IV (NIMH DISC-IV): description, differences from previous versions, and reliability of some common diagnoses. J Am Acad Child Adolesc Psychiatry 2000; 39: 28-38.

24 World Health Organization. Schedules for Clinical Assessment in Neuropsychiatry (version 2.0). WHO, 1994 
25 Fisher HL, Lereya ST, Thompson A, Lewis G, Zammit S, Wolke D. Childhood parasomnias and psychotic experiences at age 12 years in a United Kingdom birth cohort. Sleep 2014; 37: 475-82.

26 American Psychiatric Association. Diagnostic and Statistical Manual of Mental Disorder (4th edn) (DSM-IV). American Psychiatric Association, 1994.

27 Wolke D. Feeding and sleeping across the lifespan. In Development Through Life: A Handbook for Clinicians (ed M Rutter and D Hay): 517-57. Blackwell Scientific Publications, 1994.

28 Wechsler D. Manual for the Wechsler Intelligence Scale for Children (3rd edn) (WISC-III). Psychological Corporation, 1991.

29 Bowen E, Heron, J, Waylen, A, Wolke, D. Domestic violence risk during and after pregnancy: findings from a British longitudinal study. BJOG 2005; 112 1083-9.

30 Goodman R, Ford T, Richards H, Gatward R, Meltzer H. The development and well-being assessment: description and initial validation of an integrated assessment of child and adolescent psychopathology. J Child Psychol Psychiatry 2000; 41: 645-55.

31 Angold A, Costello EJ, Messer SC, Pickles A. Development of a short questionnaire for use in epidemiological studies of depression in children and adolescents. Int J Methods Psychiatr Res 1995; 5: 237-49.

32 Angold A, Erkanli A, Silberg J, Eaves L, Costello EJ. Depression scale scores in 8-17-year-olds: effects of age and gender. J Child Psychol Psychiatry 2002 43: 1052-63.

33 Koffel E, Watson D. Unusual sleep experiences, dissociation, and schizotypy: evidence for a common domain. Clin Psychol Rev 2009; 29: 548-59.

34 Laberge L, Tremblay RE, Vitaro F, Montplaisir J. Development of parasomnias from childhood to early adolescence. Pediatrics 2000; 106: 67-74.

35 St James-Roberts I. The Origins, Prevention and Treatment of Infant Crying and Sleeping Problems. An Evidence-Based Guide for Healthcare Professionals and the Families they Support. Routledge, 2012

36 Owens JA, Maxim R, Nobile C, McGuinn M, Msall M. Parental and self-report of sleep in children with attention-deficit/hyperactivity disorder. Arch Pediat Adolesc Med 2000; 154: 549-55.

37 Wolke D, Waylen A, Samara M, Steer C, Goodman R, Ford T et al. Selective drop-out in longitudinal studies and non-biased prediction of behaviour disorders. Br J Psychiatry 2009; 195: 249-56.

38 Mahowald MW, Schenck CH. Dissociated states of wakefulness and sleep. Neurology 1992; 42: 44-51; discussion 52.

39 Howland RH. Sleep-onset rapid eye movement periods in neuropsychiatric disorders: implications for the pathophysiology of psychosis. J Nerv Ment Dis 1997; 185: 730-8

40 Rechtschaffen A, Schulsinger F, Mednick SA. Schizophrenia and physiologica indices of dreaming. Arch Gen Psychiatry 1964; 10: 89-93.

41 D'Agostino A, Limosani I, Scarone S. The dreaming brain/mind: a role in understanding complex mental disorders? Front Psychiatry 2012; 3: 3.

42 Keshavan MS, Montrose DM, Miewald JM, Jindal RD. Sleep correlates of cognition in early course psychotic disorders. Schizophr Res 2011; 131 231-4.

43 Ferrarelli F, Peterson MJ, Sarasso S, Riedner BA, Murphy MJ, Benca RM, et al. Thalamic dysfunction in schizophrenia suggested by whole-night deficits in slow and fast spindles. Am J Psychiatry 2010; 167: 1339-48.
44 D'Agostino A, Aletti G, Carboni M, Cavallotti S, Limosani I, Manzone M, et al. Are delusional contents replayed during dreams? Conscious Cogn 2013; 22 $708-15$

45 Schredl M. Dream research in schizophrenia: methodological issues and a dimensional approach. ConsciousCogn 2011; 20: 1036-41.

46 Gottesmann C. The dreaming sleep stage: a new neurobiological model of schizophrenia? Neuroscience 2006; 140: 1105-15.

47 Gottesmann C, Gottesman I. The neurobiological characteristics of rapid eye movement (REM) sleep are candidate endophenotypes of depression, schizophrenia, mental retardation and dementia. Progneurobiol 2007; 81 237-50.

48 Lopez R, Jaussent I, Scholz S, Bayard S, Montplaisir J, Dauvilliers Y. Functional impairment in adult sleepwalkers: a case-control study. Sleep 2013; 36: $345-51$.

49 Hartley S, Barrowclough C, Haddock G. Anxiety and depression in psychosis: a systematic review of associations with positive psychotic symptoms. Acta Psychiatr Scand 2013; 128: 327-46.

50 Terr LC, Bloch DA, Michel BA, Shi H, Reinhardt JA, Metayer S. Children's symptoms in the wake of challenger: a field study of distant-traumatic effects and an outline of related conditions. Am J Psychiatry 1999; 156: 1536-44.

51 Schreier A, Wolke D, Thomas K, Horwood J, Hollis C, Gunnell D, et al. Prospective study of peer victimization in childhood and psychotic symptoms in a nonclinical population at age 12 years. Arch Gen Psychiatry 2009; 66: $527-36$

52 Fisher HL, Schreier A, Zammit S, Maughan B, Munafò MR, Lewis G, et al. Pathways between childhood victimization and psychosis-like symptoms in the ALSPAC birth cohort. Schizophr Bull 2013; 39: 1045-55.

53 American Psychiatric Association. Diagnostic and Statistical Manual of Mental Disorders (5th edn) (DSM-5). American Psychiatric Association, 2013.

54 Neylan TC, Marmar CR, Metzler TJ, Weiss DS, Zatzick DF, Delucchi KL, et al. Sleep disturbances in the Vietnam generation: findings from a nationally representative sample of male Vietnam veterans. Am J Psychiatry 1998; 155 929-33.

55 Nielsen T, Levin R. Nightmares: a new neurocognitive model. Sleep Med Rev 2007; 11: 295-310

56 Hartman D, Crisp AH, Sedgwick $\mathrm{P}$, Borrow S. Is there a dissociative process in sleepwalking and night terrors? Postgrad Med J 2001; 77: 244-9.

57 Arseneault L, Cannon M, Fisher HL, Polanczyk G, Moffitt TE, Caspi A. Childhood trauma and children's emerging psychotic symptoms: a genetically sensitive longitudinal cohort study. Am J Psychiatry 2011; 168: 65-72.

58 Krakow B. Nightmare complaints in treatment-seeking patients in clinical sleep medicine settings: diagnostic and treatment implications. Sleep 2006; 29. 1313-9.

59 Aurora RN, Zak RS, Auerbach SH, Casey KR, Chowdhuri S, Karippot A, et al. Best practice guide for the treatment of nightmare disorder in adults. J Clin Sleep Med 2010; 6: 389-401.

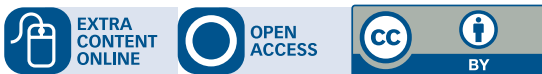

